\title{
Study on the Urban and Rural Differences in Education Quality Supervision and Instruction of Public Interest Kindergartens in Chongqing
}

\author{
Li Zonglu", Cai Hongmei ${ }^{2}$, , Liao Linlin ${ }^{2}$ \\ ${ }^{1}$ Taizhou Vocational College of Science \& Technology, Zhejiang, China \\ ${ }^{2}$ Chongqing Normal University, School of Education, Chongqing, China
}

Email address:

408496475@qq.com (Li Zonglu), 527753713@qq.com (Cai Hongmei), 571704592@qq.com (Liao Linlin)

${ }^{*}$ Corresponding author

\section{To cite this article:}

Li Zonglu, Cai Hongmei, Liao Linlin. Study on the Urban and Rural Differences in Education Quality Supervision and Instruction of Public Interest Kindergartens in Chongqing. Education Journal. Special Issue: Pathway to Quality Preschool Education: Chinese Perspectives. Vol. 9, No. 1, 2020, pp. 29-36. doi: 10.11648/j.edu.20200901.15

Received: January 8, 2020; Accepted: February 27, 2020; Published: March 17, 2020

\begin{abstract}
Supervision and instruction of education quality is an important guarantee for public interest kindergartens to realize their public welfare, popularization and high quality. The purpose of the study is to investigate the current status of supervision and instruction quality of public interest kindergartens in urban and rural areas of Chongqing. The study was carried out on 325 teachers, 85 directors and 51 other teaching staff from public interest kindergartens. Data collected from the respondents were coded and entered into the computer for analysis using SPSS version-20 for windows. The results show that the education quality supervision of public interest kindergartens is generally at a satisfactory level. There is no significant difference between urban and rural public interest kindergartens in the education quality supervision, and the public interest kindergartens in urban and rural areas show a trend of equal development in terms of structural quality. However, there are significant differences in the supervision quality standards and the professionalism of supervision personnel between urban and rural public interest kindergartens, those of which in urban areas are better than those in rural areas. Findings highlight that it should formulate a developmental preschool education quality evaluation system, perfect the quality supervision mechanism, implement special training for supervision personnel, strengthen the quality supervision of public interest kindergartens in townships and improve the quality support mechanism in order to realize the balanced and high-quality development of public interest kindergartens both in urban and rural areas.
\end{abstract}

Keywords: Public Interest Kindergarten, Preschool Education Quality, Supervision and Instruction of Education Quality

\section{Introduction}

Public interest kindergartens are an important measure taken by the Chinese government to promote equity in preschool education and improve its quality. Public interest kindergartens meet the basic standards set by the government, which recruit students facing the public school-age children, charge reasonable fees, and protect and educate children in a scientific way, reflecting the popularity of education objects, the priority of disadvantaged groups and the fairness of implementation results [1]. In the past two years, the Chinese government has placed special emphasis on improving the education quality of public interest kindergartens, putting forward the suggestions of "perfecting the quality evaluation and monitoring system" and "establishing the supervision and accountability mechanism". The definition of quality might therefore need revision at some point and should not be considered as a static concept. The quality of preschool education is the sum of various characteristics of children's environment and experience that are closely related and promote their development [2]. The quality of pre-school education mainly consists of structural quality (mainly the factors that are easily quantifiable and manipulated, such as teachers level, teacher-child ratio, class size and safety), process quality (elements that are directly related to early childhood learning and development, such as teacher-child 
interaction, curriculum and teaching, teacher education input, family-kindergarten connection and educational environment) and outcome quality (the development of children in various aspects). Therein, the outcome quality is the result of the interaction between conditional quality and process quality $[3$, 4]. Supervision and instruction of education quality of public interest kindergartens is a process of supervising, evaluating and feeding back the education quality of kindergartens according to the relevant national education policies and the provisions of laws and regulations, aiming at comprehensively improving the care and education quality of kindergartens.

The study shows that the quality level of public interest education in China is uneven and generally low, and meanwhile the evaluation, monitoring, supervision and other mechanisms and systems for the care and education quality are not sound enough [5]. Besides, the quality of preschool education in urban and rural areas is greatly different and the education quality of urban kindergartens is significantly higher than that of rural kindergartens [6]. This study investigates the urban-rural differences in education quality supervision of public interest kindergartens, aiming to put forward corresponding countermeasures and suggestions for existing problems by exploring the urban-rural differences in education quality supervision of public interest kindergartens and provide some reference for promoting the balanced development of preschool education in urban and rural areas and improving the quality of preschool education.

\section{Methods}

\subsection{Participants}

This study conducted a survey on the urban-rural differences in the education quality supervision of public interest kindergartens in Chongqing from December 2018 to
April 2019, with the directors, full-time teachers and other teaching staff (mainly child-care workers) as the objects. Directors and full-time teachers are the direct participants of the development of education quality of public interest kindergartens, who are deeply aware of the quality problems in the development process. It is found that directors and full-time teachers play a decisive role in the quality of preschool education when the structural quality reaches the national standard. Thus, this study selects the directors and full-time teachers as the objects [7]. 623 questionnaires were given out and 461 valid questionnaires were collected, with an effective recovery rate of $74 \%$, including 348 persons from urban areas (cities and counties) and 113 persons from rural areas (towns and villages). The detailed distribution is as shown in table 1 .

Table 1. Sample Distribution $(N=461)$.

\begin{tabular}{clll}
\hline & urban areas & rural areas & total \\
\hline Directors & 56 & 29 & 85 \\
Full-time teachers & 253 & 72 & 325 \\
Other teaching staff & 39 & 12 & 51 \\
Total & 348 & 113 & 461 \\
\hline
\end{tabular}

\subsection{Instruments}

The study compiles a questionnaire about "Supervision and instruction of education quality of public interest kindergartens in Chongqing (preliminary test)" and selects one public interest kindergarten from the main urban area and one district or county of Chongqing, respectively. A total of 50 managers and teachers of public interest kindergartens were selected to carry out the preliminary test. After the relevant statistical analysis, a formal questionnaire was formed. The Cronbach's $\alpha$ coefficient of the formal questionnaire is larger than 0.8 , which meets the reliability requirements. The formal questionnaire consists of three parts, with a total of 37 items, as shown in table 2.

Table 2. Composition of the Supervision and Instruction Investigation Dimensions for the Education Quality of Public Interest Kindergartens.

\begin{tabular}{|c|c|c|}
\hline The basic information & $\begin{array}{l}\text { supervision, type of kindergarten (pul } \\
\text { kindergartens, the number of times o }\end{array}$ & $\begin{array}{l}\text { background, level of kindergarten, geographical location, conditions under government } \\
\text { c or private; Whether it is a public interest kindergarten), the contact status of designated } \\
\text { upervision received in the past year }\end{array}$ \\
\hline \multirow{5}{*}{$\begin{array}{l}\text { External supervision and } \\
\text { instruction of education } \\
\text { quality }\end{array}$} & $\begin{array}{l}\text { The degree of attention to the quality } \\
\text { of education }\end{array}$ & $\begin{array}{l}\text { Teacher-child ratio, venues and facilities, safety and health, learning and games, staff } \\
\text { qualification and management, kindergarten planning and curriculum, early childhood } \\
\text { development, working conditions. }\end{array}$ \\
\hline & Quality of supervisors & $\begin{array}{l}\text { Familiar with preschool education policies and regulations, good at finding educational } \\
\text { problems and putting forward suggestions, familiar with preschool education practice } \\
\text { and practical supervision work }\end{array}$ \\
\hline & $\begin{array}{l}\text { Supervision standard system and } \\
\text { implementation }\end{array}$ & $\begin{array}{l}\text { Scientific supervision standard, multiple data collection methods, true data collected and } \\
\text { good privacy protection without causing harm or interfering with the normal educational } \\
\text { order. }\end{array}$ \\
\hline & Stakeholder participation & Participation of teaching staff and parents \\
\hline & Evaluation of supervision effect & $\begin{array}{l}\text { Find out the quality problems and shortcomings, conduct timely feedback, clarify the } \\
\text { causes of the problems and improve the quality }\end{array}$ \\
\hline \multirow{4}{*}{$\begin{array}{l}\text { Internal supervision and } \\
\text { instruction of education } \\
\text { quality }\end{array}$} & $\begin{array}{l}\text { The degree of attention to the quality } \\
\text { of education }\end{array}$ & $\begin{array}{l}\text { Creation and utilization of class environment, organization and care of one-day life, } \\
\text { support and guidance of game activities, planning and implementation of educational } \\
\text { activities, interpersonal activities (interaction between teachers and children, interaction } \\
\text { between teachers and staff and their interaction with parents) }\end{array}$ \\
\hline & Quality of supervisors & The level of professional quality of supervisors \\
\hline & Supervision standard and system & Supervision standard and system \\
\hline & Evaluation of supervision effect & The supervision work has been carried out effectively and achieved remarkable results \\
\hline
\end{tabular}


The basic information section of the multiple choice questions of the questionnaire is filled out according to the actual situation, and the remaining options are designed in the form of a five-point scale; "1= very disagree", "2= disagree", "3= uncertain", "4= agree" and "5= very agree". The sequencing questions are answered in order of importance from the highest to the lowest, and the percentage of the total number of top choices is calculated for statistical analysis. In order to fully and deeply understand the urban-rural differences in the supervision and instruction of education quality of public interest kindergartens, the study also interviewed a total of 9 kindergarten principals, teachers, supervisors and other personnel responsible for supervision from three aspects: the basic situation of the subject and object of supervision, the process and method of supervision, and the actual effect and suggestions. Spss20.0 is used for data analysis in this study.

\section{Results}

\subsection{Comparison of the Differences in the Education Quality Supervision of Public Interest Kindergartens Between Urban and Rural Areas}

The study investigates the overall situation of supervision and instruction of education quality in public interest kindergartens between urban and rural areas, and the results are as shown in Table 3.

Table 3. Differences in Supervision and Instruction of Education Quality of Public Interest Kindergartens between Urban and Rural Areas (N = 461).

\begin{tabular}{lllll}
\hline Dimension & N & M & SD & \\
\hline Urban areas & 348 & 4.25 & 0.53 & 2.410 .11 \\
Rural areas & 113 & 4.17 & 0.45 & \\
\hline
\end{tabular}

As can be seen from the above table, the overall mean value of supervision and instruction of education quality in public interest kindergartens from urban areas is $(\mathrm{M}=4.25$, $\mathrm{SD}=0.53$ ) and that in public interest kindergartens from rural areas is $(\mathrm{M}=4.17, \mathrm{SD}=0.45)$ in Chongqing. It can be seen that the overall quality supervision and instruction of public interest kindergartens in urban and rural areas of Chongqing is in a satisfactory state. At the same time, according to the result of $\mathrm{T}$ test $(p>0.05)$, there is no significant difference in the overall education quality supervision between urban public interest kindergartens and rural ones. However, from the overall mean value of urban and rural areas, there are subtle differences between them, and the supervision in urban areas is slightly better than that in rural areas.

\subsection{Rural-urban Differences in the Supervision and Instruction of Education Quality of Public Interest Kindergartens in Various Dimensions}

\subsubsection{The Differences Between Urban and Rural Areas in the Attention Paid to Quality Factors by Education Quality Supervisors of Public Interest Kindergartens}

This study investigates the differences between urban and rural areas in the attention that supervisors pay to education quality from two aspects: internal and external education quality supervision. First, the differences between urban and rural areas in the degree of attention paid to education quality by internal education quality supervisors are as shown in Figure 1.

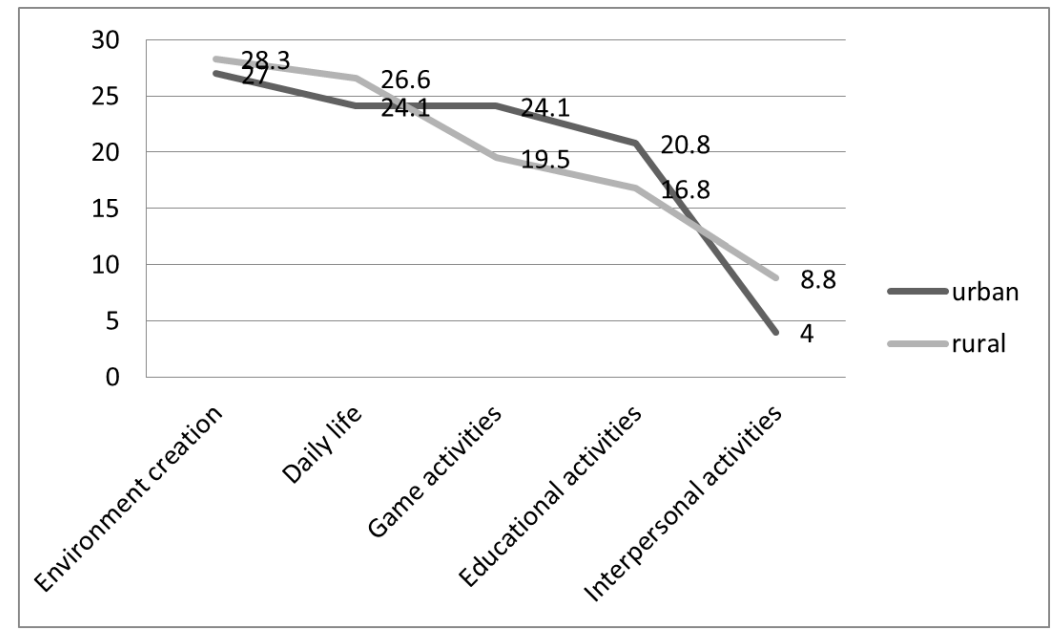

Figure 1. Differences between Urban and Rural Areas in the Attention Paid to Quality Factors by Internal Education Quality Supervisors of Public Interest Kindergartens.

As can be seen from figure 1 , on the whole, the internal education quality supervisors of public interest kindergartens in urban and rural areas attach similar importance to various factors of education quality, which are environment creation, daily life, game activities, educational activities and interpersonal activities, respectively in order of importance. It 
shows that the internal supervision focuses on the structural quality of the environment, and the attention paid to the important process quality factors of the interpersonal activities (the interaction between teachers and children, the interaction between teachers and other teaching staff and their interaction with the parents) is not enough.

Secondly, the differences between urban and rural areas in the degree of attention that external education quality supervisors pay to education quality factors are as shown in figure 2 .

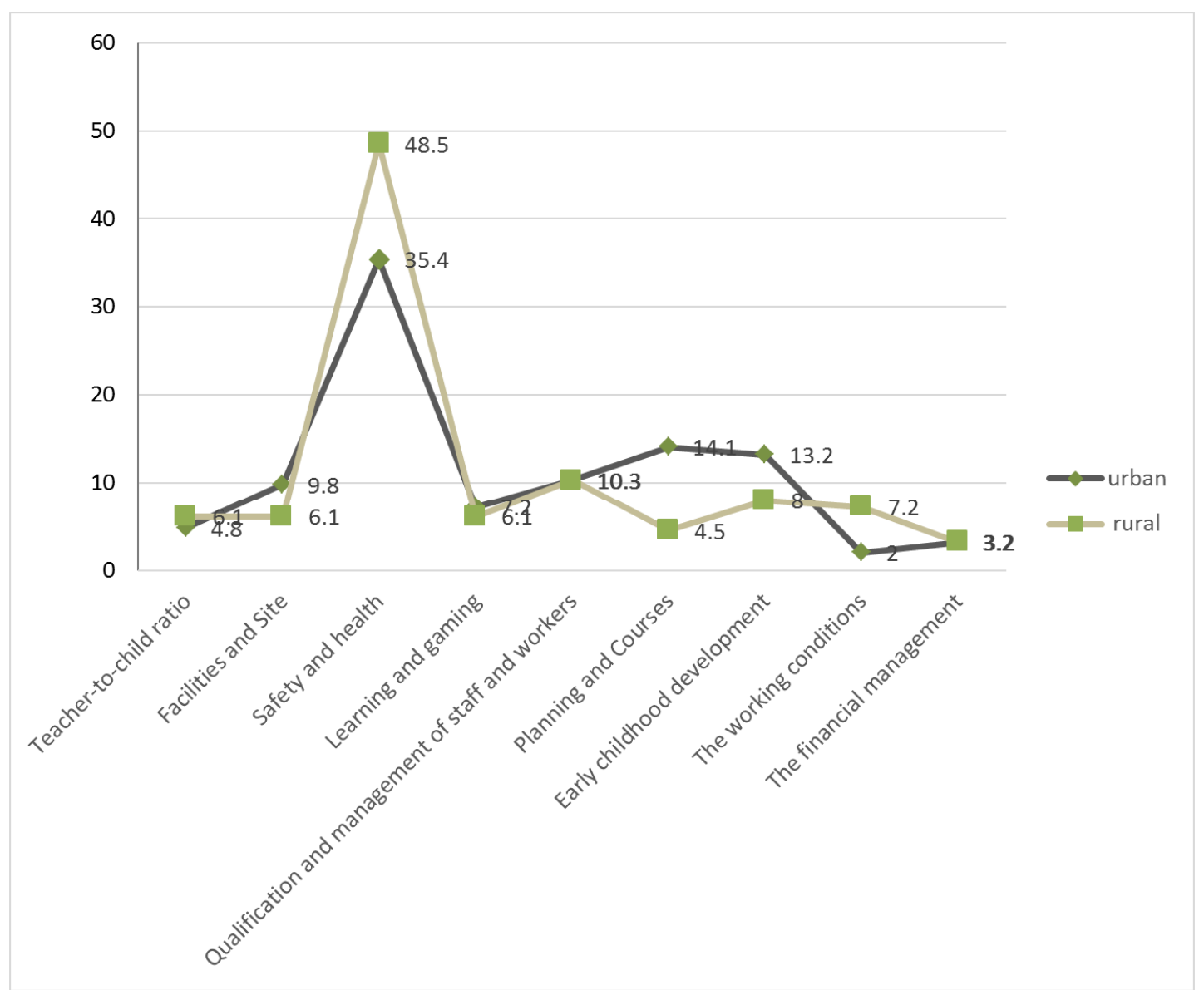

Figure 2. Urban and Rural Differences in Attention Paid to Quality Factors by External Education Quality Supervisors in Public Interest Kindergartens $(N=461)$.

As can be seen from figure 2, on the whole, there is no big difference in the degree of attention paid to the education quality factors in the external supervision and instruction of education quality of public interest kindergartens in urban and rural areas, but there are some subtle differences. (1) It is basically close or consistent in urban and rural areas in terms of the level of attention paid to the five factors of teacher-child ratio, facilities and venues, play and study, staff qualifications and management and financial management, indicating that after the state promulgated and implemented the "Measures for the Evaluation of the Conduct of Kindergartens" in 2017, the development of public interest kindergarten education in urban and rural areas has shown a trend of equalization in the structure and quality. (2) There are great differences between urban and rural areas in the emphasis on the three quality elements of kindergarten planning and curriculum development, child development and working conditions. Therein, in terms of the importance attached to the two elements of kindergarten planning and curriculum development, and child development, it is higher in the urban area than the rural, indicating that the external supervision of the urban area attaches more importance to the process quality elements than the township. At the same time, in terms of the importance attached to working conditions, it is significantly higher in the township than the urban area, indicating that there are great differences between urban and rural areas in terms of teachers' work burden and time, salary and welfare as well as vacation and overtime work arrangement.

\subsubsection{Rural-urban Differences in Various Dimensions of Supervision and Instruction of Education Quality in Public Interest Kindergartens}

There is no significant difference in supervision and instruction of education quality of public interest kindergartens between urban and rural areas, but it does not mean that there is no great difference among various dimensions. Therefore, the study tested the differences among the dimensions of public interest kindergarten education in urban and rural areas, as shown in Table 4 and Table 5 
Table 4. Differences between Urban and Rural Areas in the Supervision and Instruction of Education Quality of Public Interest Kindergartens ( $N=461)$.

\begin{tabular}{lllll}
\hline & \multicolumn{2}{c}{ Internal supervision } & & \\
\cline { 2 - 5 } & Supervision system & Supervision standard & Professionalism of personnel & Supervision effect \\
\hline Urban & & & 4.4 \\
M & 4.40 & 4.39 & 4.39 & 0.64 \\
SD & 0.58 & 0.63 & 0.60 & 4.25 \\
Rural & & & 0.57 \\
M & 4.32 & 4.12 & 4.18 & $0.02^{*}$ \\
SD & 0.52 & 0.60 & 0.45 & $0.00^{* *}$ \\
T & $0.03^{*}$ & $0.00^{* *}$ & & \\
\hline
\end{tabular}

As can be seen from table 4, there are differences between urban and rural areas in the dimensions of internal and external education quality supervision of kindergartens. First of all, there are urban and rural differences in the four dimensions of internal supervision and instruction of education quality: supervision system, supervision standard, professionalism of personnel and supervision effect $(p<0.05)$. Among them, there is a significant difference between urban and rural areas in the two dimensions of supervision standard and professionalism of personnel $(p \leq 0.00<0.01)$. It shows that the internal supervision and instruction of education quality of public interest kindergartens in urban areas is better than that in rural areas. The investigation indicates that the managers of public interest kindergartens in rural areas are mostly primary school transfer teachers, who are restricted by professional background and work experience, and their ability to organize and implement internal supervision and instruction needs to be further improved.

Table 5. Differences between Urban and Rural Areas in the Dimension of External Supervision and Instruction of Education Quality of Public Interest Kindergartens $(N=461)$.

\begin{tabular}{llll}
\hline Professionalism of personnel & Supervision standard & Process and method & Supervision effect \\
\hline Urban & & & 4.24 \\
M 4.19 & 4.18 & 0.74 & 0.66 \\
SD 0.74 & 0.65 & & 4.15 \\
Rural & & 0.65 & 4.17 \\
M 4.16 & 4.15 & 0.82 & 0.62 \\
SD 0.56 & 0.50 & $0.00^{* *}$ & 0.47 \\
T $0.02^{*}$ & & \\
\hline
\end{tabular}

Secondly, there are differences between urban and rural areas in the two dimensions of professionalism of personnel and supervision standard $(p<0.05)$ and the differences are very significant $(p<0.01)$. It also shows that the current quality standards of preschool education are too unified and do not clarify the differences between urban and rural areas, which need to be improved and optimized.

Further statistics shows that there are significant differences $(p<0.01)$ among the specific items of internal supervision and instruction of education quality between urban and rural areas, including "The staff serving as the education quality supervisors are very professional", "The standard of education quality evaluation is scientific and reasonable" and "The work of supervision and instruction of education quality has achieved remarkable results" $(p<0.01)$. Among the specific items of external supervision and instruction of education quality, the two items of "the supervision and instruction of education quality personnel is very professional in preschool education" and "a set of clear and reasonable quality indicators or quality standards are adopted" are with significant differences between urban and rural areas $(p<0.01)$. The differences between urban and rural areas in the education quality supervision of public interest kindergartens further indicate that the professionalism of the supervision personnel and the quality standards of supervision have an important influence on the quality of supervision and instruction.

\section{Discussion and Recommendations}

\subsection{Discussion}

\subsubsection{The Differences Between Urban and Rural Areas in the Education Quality Supervision and Instruction of Public Interest Kindergartens}

The quality supervision and instruction of public interest kindergartens in Chongqing is in a satisfactory state and there is no significant urban and rural difference. However, compared with the mean value of urban and rural areas in supervision and instruction, there are subtle differences between them and the condition of urban areas is slightly better than that of the rural areas. These findings are similar to the conclusions of researchers that the pre-school education quality in cities is better than that in rural areas of China [6]. Therefore, this study believes that the urban and rural differences in the quality supervision and instruction of preschool education may be one of the factors leading to the difference in the quality of preschool 
education between urban and rural areas. At the same time, the internal supervision and instruction of education quality of public interest kindergartens in urban areas is significantly better than that of rural public interest kindergartens. Due to the influence of teachers' educational background, professional background, working conditions, wages and welfare in rural public interest kindergartens, the ability to improve the education quality according to the supervision opinions is limited, which further indicates that the weak development of rural preschool teachers cannot effectively guarantee the development quality of rural preschool education [8].

\subsubsection{Different Emphasis on Structural Quality and Process Quality in the Supervision and Instruction of Educational Quality of Public Interest Kindergartens}

It is found that both urban and rural public interest kindergartens attach more importance to the structural quality than the process quality in the internal supervision and instruction of education quality. Process quality factors have a more important impact on the preschool education quality, especially the quality of teacher-child interaction is the main educational mechanism to promote the development of children's ability [9]. Therefore, it is considered that the attention paid to the process quality factors by internal supervision, such as game activity and human activity, is not enough and it is also a factor that leads to the poor overall level of interaction quality of the kindergarten and the lower education and game quality of urban and rural kindergartens [10].

\subsubsection{Different Supervision Standards Between Urban and Rural Areas in the Education Quality Supervision and Instruction of Public Interest Kindergartens}

The research shows that there are significant differences between urban and rural areas in the education quality supervision and instruction of public interest kindergartens in terms of the supervision standards and the professionalism of supervisors, which may be one of the reasons for the differences in the supervision and instruction of education quality in urban and rural areas. Firstly, The quality assessment criteria for preschool education institutions are the most effective policy tool in education, which not only assess the quality level of preschool education institutions, find problems in the and ensure that all children enjoy the education with minimum standards, but also bring changes and powerful sources of influence. They are the basis for ensuring fairness and improving the quality of preschool education. At present, the quality standards of preschool education in China are too uniform, and the differences between urban and rural areas are not clarified. The unified standards lead to the gap in the quality of preschool education in urban and rural areas [12]. Secondly, the professional role of supervisors is important for the quality supervision and instruction. There is evidence showing that training on monitoring practices enhances the quality and quantity of practices and enables supervisors to better use assessment for learning and development [13]. Supervisors must be trained and monitored to apply monitoring practices and tools so as to ensure that tools are properly understood and used and practices can render consistent and objective judgments [14].

\subsection{Recommendations}

The quality supervision and instruction of preschool education can provide timely information on the environment, operation, results and effect of public interest kindergartens and support for the education service work of education authorities and public interest kindergartens, and help promote the balanced and high-quality development of preschool education quality in urban and rural areas so as to realize people's good expectations to preschool education.

\subsubsection{Improve the Preschool Education Quality Standard and the Quality Supervision and Instruction System}

The index system and standard of preschool education supervision and instruction are not clearly put forward in the current "Regulations on Educational Supervision and Instruction and Interim Measures of Supervision and Instruction Administration" in China, which may be an important factor leading to the great difference in the preschool education quality between urban and rural areas. Therefore, we should first construct a perfect and developmental preschool education quality index system and standard. In the overall design of quality standards, both structural quality and process quality should be paid attention to, and consistent standards and multilevel indicators should be adopted to ensure the universality and regional suitability of quality standards. Meanwhile, in view of the reality that the process quality is relatively weak, the quality standards should be strengthened, the process quality standard with teacher-child interaction quality as the core should be refined and the process quality of urban and rural public interest kindergartens should be jointly promoted. Secondly, according to the "Interim Provisions of Educational Supervision and Instruction", we should perfect the quality supervision and instruction system, clarify the functions of supervision and instruction institutions and the division of responsibilities among the educational quality supervision and instruction subjects and formulate a standardized supervision and instruction process to ensure that the quality standards can be effectively implemented in the supervision and instruction practice.

\subsubsection{Enhance the Supervision Ability of Supervisors and Carry out Special Training}

The professional quality and supervision and instruction ability of supervisors are the key to ensuring the effect of educational quality supervision and instruction. Based on the problems existing in the professional aspects of supervisors found in the investigation, we should first improve the management system of supervisors, draw lessons from the internationally-accepted national unified qualification certification system for supervisors and clearly 
define the qualifications, responsibilities and supervision and instruction rules of supervisors to ensure that the supervisors have necessary professional knowledge and business skills from the system. Secondly, in view of the fact that there is a big gap between urban and rural areas in the preschool education quality, special supervision and instruction training can be carried out to improve the supervision and instruction ability of rural public interest kindergartens, so that it can accurately examine the problems existing in the structural quality, process quality and outcome quality of rural public interest kindergartens and provide targeted and operational guidance for quality improvement according to the actual situation of education development. Thirdly, we should strengthen the quality guidance ability of supervisors, mobilize the internal motive force of the education quality development of public interest kindergartens and actively improve the quality of nursing education by defining the concept of running kindergartens, optimizing the kindergarten curriculum system and perfecting the professional development support and the internal evaluation, supervision and instruction system of kindergartens.

\subsubsection{Strengthen the Supervision and Instruction of Rural Public Interest Kindergartens and Improve the Quality Support Mechanism}

The education quality supervision and instruction of public interest kindergartens should ensure its coverage, so that every kindergarten can get a fair and powerful development opportunity. Firstly, in view of the actual situation that the development and education quality supervision and instruction of rural public interest kindergartens, especially the privately-run kindergartens in villages for the public interest are in an obviously weak position, targeted quality supervision and instruction should be carried out. Meanwhile the government should allocate the resources of education quality supervision and instruction equitably, reform the allocation mechanism of teachers for public interest pre-school education, give priority to village-level public interest kindergartens, improve the quality and development disadvantage of rural public interest kindergartens fundamentally and establish a balanced preschool education service system between urban and rural areas. Secondly, we should improve the support mechanism for public interest kindergartens in townships, especially villages, and give them targeted help in improving the quality of process education. Finally, the supervision and instruction idea of empowerment holds that the most effective changes in care and education behaviors result from the quality improvement needs and self-improvement abilities of teachers and mangers [15]. The education quality supervision and instruction of public interest kindergartens needs to weaken the management behavior of supervisors, respect the initiative ability of kindergartens in quality improvement and ensure the basic position of kindergartens in internal quality assurance and development [16].

\section{Acknowledgements}

This paper is the periodic research result of Chongqing Education Committee / Humanities and Social Science key Base Project "Evaluation and Promotion of Urban and Rural Preschool Education Development in Minority areas of Chongqing" (Project No.: 17SKJ024).

\section{References}

[1] Xu, F. Q., Mo, W. (2012). The connotation, measuring Standard and Policy suggestion of generally beneficial Kindergarten [J]. Preschool Education Research, 7, 22-26.

[2] Litjens, I. (2013). Literature Review on Monitoring Quality in Early Childhood Education and Care [R]. Paris : Network on Early Childhood Education and Care, 6.

[3] Jalongo, M., Fennimore, B., Pattnaik, J., et al (2004). Blended perspectives: a global vision for high-quality early childhood education. Early Childhood Education Journal, 32 (3), 143-155.

[4] Huntley, \& Jill. (2001). The development of a model of process - oriented quality in early childhood services with a preschool component. Early Child Development and Care, $171(1), 47-63$.

[5] Xiaoping, Y. Yabo, F. (2019). The focus and trend of China's generally beneficial education research in the new era $[\mathrm{J}]$. Education and teaching research, 46 (02), 95-106.

[6] Mei, L., Kejian, L. (2015) Perspective of urban-rural gap in preschool education quality based on 428 class samples nationwide [J]. Research on preschool education, (6): 13-20.

[7] Xiu, M. (2015) The current situation of government support and management of public private kindergartens $[\mathrm{J}]$. Theory and Practice of Education (23): 15-17.

[8] Xiaoxia, L. (2018) Analysis on the development difference of preschool education in urban and rural China under new urbanization [J]. Journal of Minnan normal university: philosophy and social sciences, (1): 119-127.

[9] Jingchao, H. (2015) Cost sharing theory of preschool education [J]. Early childhood education, (Z3): 36-41.

[10] Xiumin, H. \& Wenting, Z. (2019) Comparison of educational quality of inclusive kindergartens under different kindergarten management systems -- and on the quality and benefit of preschool education resource allocation $[\mathrm{J}]$. Chinese journal of education, (08): 39-44.

[11] Jing, H. \& Zhonglian, Y. (2014) Rural preschool education needs reasonable quality standards [J]. Modern education management, (8): 31-35.

[12] Stuart, D., H. Aiken, K. Gould and A. Meade (2008), Evaluation of the Implementation of Kei Tua o te Pae Assessment for Learning: Early Childhood Exemplars: Impact evaluation of the Kei Tua o te Pae 2006 professional development, Ministry of Education New Zealand, Wellington.

[13] Patricia, B. (1982). Assessment and development: some theoretical and practical issues. International Journal of Educational Development, 2 (2), 107-116. 
[14] Bullough, R. \& Goldstein S L. (1984) Ideology, Teacher Role, and Resistance [J]. Teachers College Record, (2): 339-358.
[15] Manno, B. \& Vanourek, G. (2000). Beyond the Schoolhouse Door: How Charter Schools are Transforming [J]. U.S. Public Education. Phi Delta Kappan, (10): 736-744. 